\title{
Epimerization of trans-4-Hydroxy-L-proline to cis-4-Hydroxy-D-proline during Acid Hydrolysis of Collagen
}

\author{
DOMINIC D. DZIEWIATKOWSKI, VINCENT C. HASCALL, \\ AND RICK L. RIOLO \\ Dental Research Institute, The University of Michigan, \\ Ann Arbor, Michigan 48104
}

Received April 5, 1972; accepted May 1, 1972

1. trans-4-Hydroxy-L-proline is epimerized to cis-4-hydroxy-D-proline under the conditions generally used for the hydrolysis of proteins for analyses of amino acids.

2. The cis cpimcr clutcs from a column of UR-30 resin on a Beckman amino acid analyzer at the same time as threonine and hence would be undetected.

3. About $8 \%$ of the trans-4-hydroxy-L-proline in collagen can be epimerized to cis-4-hydroxy-D-proline in the hydrolysis of collagen with $6 \mathrm{~N}$ $\mathrm{HCl}$ at $110^{\circ}$ for $72 \mathrm{hr}$.

4. A procedure is described whereby the primary amino acids in hydrolyzates are deaminated with nitrous acid and removed so that the amounts of trans-4-hydroxyproline, cis-4-hydroxyproline, and proline can be determined without changing the temperature of the column of UR-30 resin on the Beckman amino acid analyzer.

In studies on the formation of ester sulfates of hydroxy amino acids (1), we observed that treatment of trans-4-hydroxy-L-proline with $6 \mathrm{~N}$ $\mathrm{HCl}, 110^{\circ}, 24 \mathrm{hr}$, yiclded a small amount of a product which eluted from a column of Beckman UR-30 resin later than trans-4-hydroxy-L-proline. This product gave a chromophore with ninhydrin with a $440 \mathrm{~nm}$ absorption profile typical of imino acid derivatives. These observations suggested that during acid hydrolysis the trans-4-hydroxy-L-proline was epimerized, in part, to a different proline derivative. The following experiments were carried out to characterize this reaction in more detail.

\section{MATERIALS AND METHODS}

Amino acid analyses were done on a Beckman model $120 \mathrm{C}$ amino acid analyzer equipped with an extended range. Typically, $0.05-0.10 \mu$ mole of a hydroxyproline sample was applied to the column $(0.9 \times 62 \mathrm{~cm})$ of 
UR-30 resin. The column was maintained at $56^{\circ}$ and eluted with citrate buffer, $\mathrm{pH} 3.25$ (2).

Values for the specific rotation of samples, $[\alpha]_{\mathrm{D}}^{26}$, were measured with a Rudolph polarimeter, using an 1 decimeter tube and a sodium lamp. In experiments on the change of the specific rotation of trans-4-hydroxyL-proline with time in $12 \mathrm{~N} \mathrm{HCl}$ at $110^{\circ}$, a Fric polarimeter, using a 2 decimeter tube and a sodium lamp, was employed.

trans-4-Hydroxy-L-proline and cis-4-hydroxy-L-proline were purchased from Calbiochem. On analysis with the amino acid analyzer each derivative gave a single peak, with the trans-4-hydroxy-L-proline eluting at $\mathbf{4 5}$ $\min$ and the cis-4-hydroxy-L-proline eluting at $54.5 \mathrm{~min}$. Values of the specific rotation of the samples are listed in Table 1 . The concentrations of the solutions used for the measurements were $2 \%(\mathrm{w} / \mathrm{v})$.

cis-4-Hydroxy-D-proline was prepared by the procedure described by Robinson and Greenstein (4). On analysis for amino acids a single peak was seen, which eluted in the same position as the cis-4-hydroxy-Lproline described above. Values for $[\alpha]_{\mathrm{D}}^{26}$ of the sample are given in Table 1.

Collagen was extracted from rat skins and was purified as described by Gross and Kirk (5).

All the other reagents were analytical grade.

Approximately $5 \mathrm{mg}$ portions of trans-4-hydroxy-L-proline were dissolved in $2 \mathrm{ml}$ of $6 \mathrm{~N} \mathrm{HCl}$. The solutions were heated in evacuated and sealed tubes for $24 \mathrm{hr}$ or $96 \mathrm{hr}$ at $110^{\circ}$. They were then either dried at $45^{\circ}$ in a flash evaporator or dried at room temperature over $\mathrm{NaOH}$ and $\mathrm{CaCl}_{2}$ in an evacuated desiccator. The residues were dissolved in citrate buffer, $\mathrm{pH} 2.2$, and analyzed on the amino acid analyzer (2).

The above experiment was repeated, except that $5 \mathrm{mg}$ portions of trans-4-hydroxy-L-proline were dissolved in $1 \mathrm{ml}$ of $6 \mathrm{~N} \mathrm{HCl}$ and the heating periods were 24 and $72 \mathrm{hr}$. At the same time, approximately 5 mg portions of collagen were similarly hydrolyzed. All of the hydroly-

TABLE 1

Values for Specific Rotation, $[\alpha]_{D}^{26}$, for Isomers of 4-Hydroxyproline

\begin{tabular}{lcccccc}
\hline & \multicolumn{2}{c}{$[\alpha]_{\mathrm{D}}^{26}$ measured in } & & \multicolumn{2}{c}{$[\alpha]_{\mathrm{D}}^{25}$ reported in } \\
\cline { 2 - 3 } \cline { 5 - 6 } \multicolumn{1}{c}{ Isomer } & $\mathrm{H}_{2} \mathrm{O}$ & $12 \mathrm{~N} \mathrm{HCl}$ & & $\mathrm{H}_{2} \mathrm{O}$ & $5 \mathrm{~N} \mathrm{HCl}$ \\
\hline trans-4-Hydroxy-L-proline & $-73.4^{\circ}$ & $-46.9^{\circ}$ & & $-76.0^{\circ} a$ & $-50.5^{\circ}$ \\
cis-4-Hydroxy-L-proline & $-59.9^{\circ}$ & $-22.7^{\circ}$ & & $-59.5^{\circ a}$ & $-18.8^{\circ} a$ \\
cis-4-Hydroxy-D-proline & $+60.7^{\circ}$ & $+23.9^{\circ}$ & & $+59.5^{\circ b}$ & - \\
\hline
\end{tabular}

"From "Handbook of Biochemistry" (3).

${ }^{b}$ From Robinson and Greenstein (4). 
zates were diluted by the addition of $2 \mathrm{ml}$ of $6 \mathrm{~N} \mathrm{HCl} .1 \mathrm{ml}$ of each was then evaporated to dryness in a flash evaporator. The residues were dis-

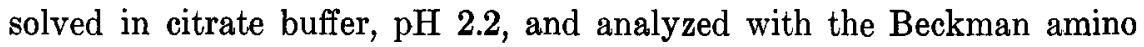
acid analyzer. To a second $1 \mathrm{ml}$ of each sample in $6 \mathrm{~N} \mathrm{HCl}, 0.5 \mathrm{ml}$ of a $3 M$ solution of sodium nitrite and $1 \mathrm{ml}$ of $8.6 \mathrm{~N} \mathrm{HCl}$ were added in that order. The resultant solutions, $0.6 M$ in nitrous acid, $6 N$ in $\mathrm{HCl}$, were heated at $100^{\circ}$ for $3 \mathrm{~min}$ and then evaporated to dryness in a flash evaporator. Each residue was dissolved in $1 \mathrm{ml}$ of $6 \mathrm{~N} \mathrm{HCl}$ and heated at $100^{\circ}$ in a water bath for $90 \mathrm{~min}$. After flash evaporation, each residue was dissolved in $1 \mathrm{ml}$ of $3 \mathrm{~N} \mathrm{HCl}$ and extracted 3 times with $3 \mathrm{ml}$ portions of ethyl ether. The aqueous phase for each sample was dried in a flash evaporator, and the residues were dissolved in citrate buffer, $\mathrm{pH}$ 2.2 , for analysis on the amino acid analyzer.

The above procedure for deamination of primary amino acids is a modification of the procedure of Hamilton and Ortiz (6). The amino acids, proline and hydroxyproline, are stable to the procedure and can be recovered quantitatively.

$2 \mathrm{gm}$ of trans-4-hydroxy-L-proline was dissolved in $100 \mathrm{ml}$ of concentrated $\mathrm{HCl}$, approximately $12 N$ (Baker Analyzed Reagent, sp.gr. 1.185$1.192,36.5-38.0 \%$ ). The solution was maintained at $110^{\circ}$ for up to 96 $\mathrm{hr}$, except for an aliquot which was set aside at $0^{\circ}$ for the same period of time. The optical rotations of aliquots of the solution were measured after various intervals of time. At the same times aliquots were flash evaporated and analyzed on the amino acid analyzer. The experiment was repeated with a solution of $2.5 \mathrm{gm}$ of trans-4-hydroxy-I-proline in $100 \mathrm{ml}$ of $12 \mathrm{~N} \mathrm{HCl}$. However, samples were removed for analysis after intervals of time up to 12 days.

\section{RESULTS}

When trans-4-hydroxy-L-proline was dissolved in $6 \mathrm{~N} \mathrm{HCl}$ and immediately dried at $45^{\circ}$ with a flash evaporator, or more slowly at room temperature over $\mathrm{NaOH}$ and $\mathrm{CaCl}_{2}$ in an evacuated desiccator, only one component, with an elution time of $\mathbf{4 5}$ min, was observed on the column of UR-30 resin. On the other hand, if such solutions were heated at $110^{\circ}$, the amount of material in the effluent at $45 \mathrm{~min}$ decreased and a correspondingly increased amount of ninhydrin-reactive material was found at $54.5 \mathrm{~min}$ (Table 2). Similar results were obtained when collagen was hydrolyzed with $6 \mathrm{~N} \mathrm{HCl}$ (Table 3). The fact that the isomer formed from trans-4-hydroxy-L-proline eluted from the column at the same position as a standard of cis-4-hydroxy-L-proline (Table 4) suggested that the isomer was either the $\mathrm{D}$ or $\mathrm{L}$ form of cis-4-hydroxyproline or a mixture of both. 
TABLE 2

Epimerization of trans-4-L-Hydroxyproline at $110^{\circ}$ in $6 \mathrm{~N} \mathrm{HCl}$

\begin{tabular}{clc}
\hline Time of heating, hr & \multicolumn{1}{c}{ Treatment } & $\begin{array}{c}\text { Epimer found, } \\
\text { \% of total }\end{array}$ \\
\hline 0 & Flash evaporation at $45^{\circ}$ & 0 \\
0 & Desiccation at room temp. & 0 \\
24 & Flash evaporation at $45^{\circ}$ & 10.2 \\
24 & Desiccation at room temp. & 5.8 \\
96 & Flash evaporation at $45^{\circ}$ & 27.8 \\
96 & Desiccation at room temp. & 31.2 \\
\hline
\end{tabular}

The hydrolyzates were evaporated to dryness either in a flash evaporator at $45^{\circ}$ or at room temperature in an evacuated desiccator which contained pellets of $\mathrm{NaOH}$ and $\mathrm{CaCl}_{2}$. The residues were dissolved in sodium citrate buffer, $\mathrm{pH} 2.2$, for analysis on an amino acid analyzer.

a The amount of epimer formed was calculated assuming that it yielded the same amount of chromophore per mole as did trans-4-hydroxy-L-proline.

TABLE 3

Epimerization of trans-4-L-Hydroxyproline of Collagen at $110^{\circ}$ in $6 \mathrm{~N} \mathrm{HCl}$

\begin{tabular}{lclc}
\hline Material & $\begin{array}{c}\text { Time of } \\
\text { heating, hr }\end{array}$ & Treatment & $\begin{array}{c}\text { Epimer found, } \\
\text { \% of total }\end{array}$ \\
\hline trans-4-L-hydroxyproline & 24 & Evap. only & 2.4 \\
& 24 & D \& E & 2.8 \\
& 72 & Evap. only & 7.4 \\
Collagen & 72 & D \& E & 8.7 \\
& 24 & D \& E & 2.7 \\
& 72 & D \& E & 8.1
\end{tabular}

trans-4-Hydroxy-L-proline and collagen were each heated in $6 \mathrm{~N} \mathrm{HCl}$ for the specified periods of time. Subsequently a portion was analyzed directly and a second equal portion was treated with nitrous acid as detailed in the text.

${ }^{a} \mathrm{D} \& \mathrm{E}$, deamination and evaporation.

TABLE 4

Time of Appearance of Some Amino Acids in Eftluent from Column of UR-30 Resin

\begin{tabular}{lc}
\hline \multicolumn{1}{c}{ Amino acid } & Elution time, min \\
\hline trans-4-Hydroxyproline & 45.0 \\
Aspartic acid & 45.5 \\
cis-4-Hydroxyproline & 54.5 \\
Threonine & 55.0 \\
Proline & 73.0
\end{tabular}

A Beckman amino acid analyzer was used as specified (2). The temperature of the long column was $56^{\circ}$. 
The experiments on the change in the optical rotation of a solution of trans-4-hydroxy-L-proline in $12 \mathrm{~N} \mathrm{HCl}$ at $110^{\circ}$ as correlated with the appearance of an isomer lead to the conclusion that the isomer is cis-4hydroxy-D-proline. The plot of observed values for $[\alpha]_{\mathrm{D}}^{25}$ against per cent of trans-4-hydroxyproline present in the solution after various incubation times (Fig. 1) yields a straight line which extrapolates to a

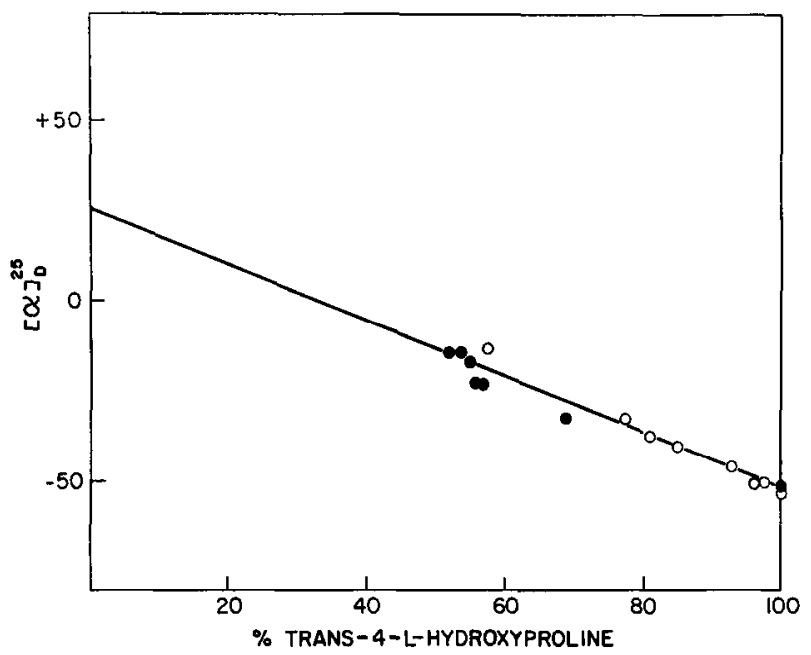

FIg. 1. The curve indicates the optical rotation observed for a solution of trans4-hydroxy-L-proline as it was epimerized on heating at $110^{\circ} \mathrm{C}$ in $12 \mathrm{~N} \mathrm{HCl}$ as a function of the relative amount of the trans epimer present: $(O)$ from experiment 1, (O) from experiment 2. The extrapolated value for $[\alpha]_{D}^{25}$ at $0 \%$ trans epimer is positive, suggesting that the cis epimer formed is of the D series. The graph shows the best first-order least-squares line through the data.

value of $[\alpha]_{\mathrm{D}}^{25}$ of $+25^{\circ}$ for the isomer (0 per cent trans-4-hydroxy-Lproline). This agrees well with a value of $[\alpha]_{\mathrm{D}}^{26}$ of $+23.9^{\circ}$ determined in $12 \mathrm{~N} \mathrm{HCl}$ for a sample of cis-4-hydroxy-D-proline prepared according to Robinson and Greenstein (4) (Table 1). Indeed, the acid conditions used in the experiment are similar to those these authors used to epimerize the $\alpha$-carbon of 4-hydroxyprolines, namely, boiling in a mixture of acetic anhydride and glacial acetic acid.

When the transformation of trans-4-hydroxy-L-proline to cis-4-hydroxy-D-proline was related to time of heating in $12 \mathrm{~N} \mathrm{HCl}$ at $110^{\circ}$, it was found that after 6 days there was nearly an equal amount of the two forms in solution and that the relative concentrations of the epimers do not change thereafter (Fig. 2). The equilibrium constant for the reaction under these conditions, then, is about 1 . It is noteworthy that the optical rotation of the solution was the same at the end of 12 days as at the 


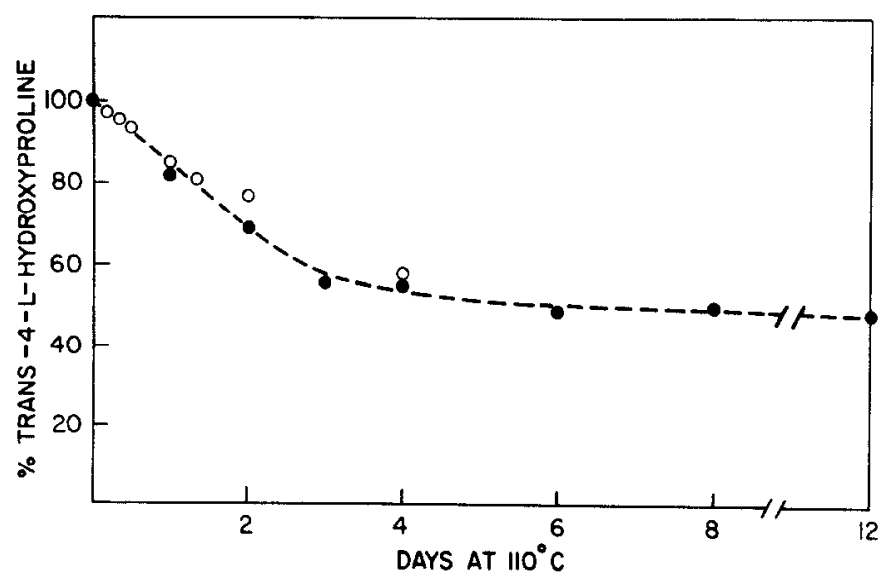

Fia. 2. Transformation of trans-4-hydroxy-L-proline to cis-4-hydroxy-D-proline with time in $12 \mathrm{~N} \mathrm{HCl}$ at $110^{\circ}$. The data have been plotted against the time the solution was incubated at $110^{\circ}$.

beginning of the experiment if the solution was kept at $0^{\circ}$, and the cis epimer was not detected when the solution was analyzed with the amino acid analyzer.

Table 4 indicates the elution times of the 4-hydroxyproline derivatives and of the amino acids which interfere with their detection, aspartic acid and threonine, when standard conditions are used for the analyses. For adequate quantitation of trans-4-hydroxyproline and aspartic acid it was suggested by Spackman, Stein, and Moore (7) that an analysis of the hydrolyzates be run at $30^{\circ}$. However, no conditions for resolving cis-4hydroxyproline in amino acid analyses have been reported, and the probable presence of this derivative in acid hydrolyzates of collagen has not been detected. Both 4-hydroxyproline derivatives can be measured using standard conditions on the amino acid analyzer if the primary amino acids are first deaminated and removed by the procedures described in "Materials and Methods." Figures 3 and 4 show analyses for a hydrolyzate of collagen, before and after such treatment. In this example, about $8 \%$ of the trans-4-hydroxyproline has been epimerized to the cis derivative, during the hydrolysis for $72 \mathrm{hr}$, which is readily apparent in Fig. 4 (see also Table 3).

\section{DISCUSSION}

trans-4-Hydroxy-L-proline was first isolated from hydrolyzates of gelatin in 1902 by Fischer (8). It is regarded as a characteristic of the collagen and its concentration in tissues is frequently the basis for the calculation of the approximate concentration of collagen. However, cis-4- 


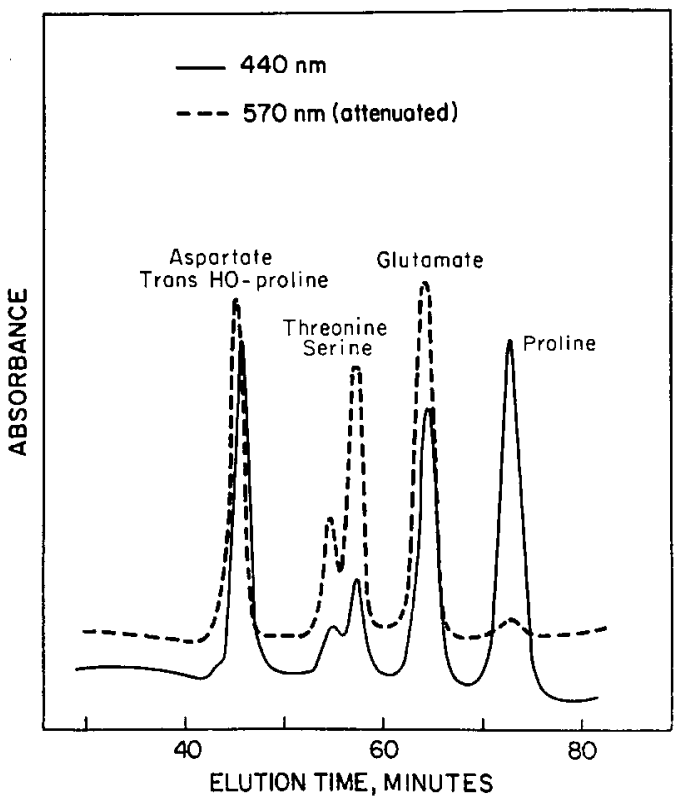

Fig. 3. Elution pattern, 40 to $80 \mathrm{~min}$, of hydrolyzate of collagen from an amino acid analyzer run at $56^{\circ} \mathrm{C}$ according to the directions supplied by the manufacturer (2). Note that trans-4-hydroxyproline is not resolved from aspartic acid and the "peak" for threonine does not indicate the presence of the cis-4-hydroxyproline.

hydroxy-L-proline (allo-hydroxy-L-proline) also occurs in nature. The latter has been isolated from the toxic peptide of Amanita phalloides by Wieland and Witkop (9) and from Santalum album L. by Radhakrishman and Giri (10).

The observation that trans-4-hydroxy-L-proline is epimerized when heated in $6 \mathrm{~N} \mathrm{HCl}$ (1) raised the question as to the nature of the epimer and whether it is formed when collagens are hydrolyzed. The results as given in this paper support the conclusion that the epimer formed is cis-4-hydroxy-D-proline. Moreover, on hydrolysis of collagens it is also formed in proportion to the time taken for the hydrolysis. Since a system is frequently employed for amino acid analysis (2) in which the cis-4-hydroxyproline is eluted simultaneously with threonine, the presence of the cis epimer will remain undetected and the concentration of the trans epimer may be underestimated. The data in this paper indicate that the per cent of cis-4-hydroxy-D-prolinc formed during the usual hydrolysis of proteins which contain the trans-4-hydroxy-L-proline may be as much as $10 \%$, depending upon time for hydrolysis. The amount of 


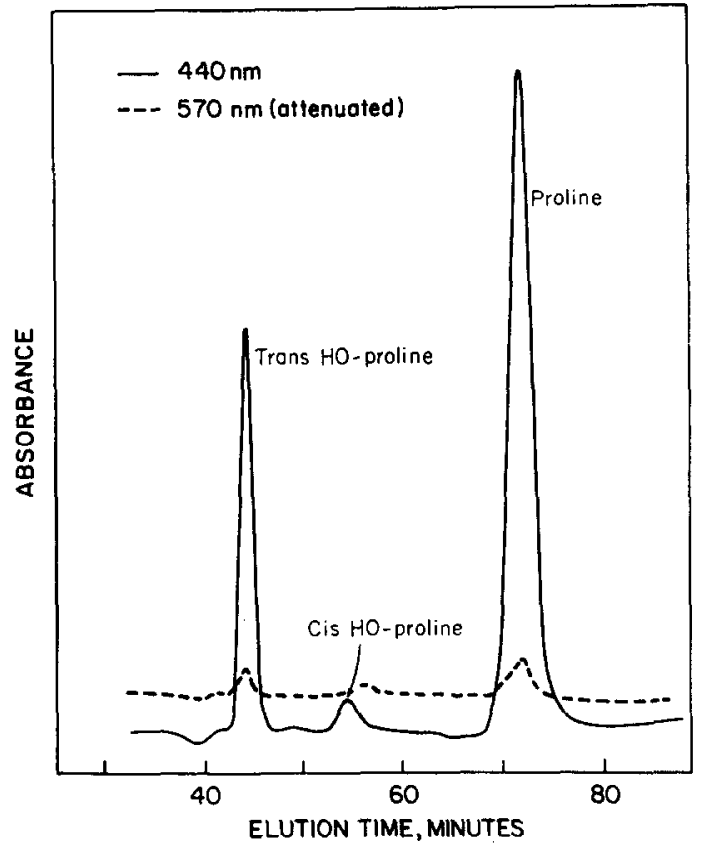

Fig. 4. Elution pattern, 40 to $80 \mathrm{~min}$, of hydrolyzates of collagen after deamination of primary amino acids. The column conditions are the same as for Fig. 3 except that twice as much material was chromatographed. The trans-4-hydroxyproline and its cis epimer are now readily apparent.

the cis epimer in a hydrolyzate can be readily quantitated if the primary amino acids are deaminated by the use of nitrous acid and removed from the hydrolyzate. Such a procedure also allows for good quantitative analyses of all the proline and hydroxyproline in the sample using standard conditions for amino acid analysis.

\section{ACKNOWLEDGMENTS}

We are grateful to Dr. J. Distler of the Rackham Research Unit, The University of Michigan, for checking the optical rotations of the amino acids.

This work was supported by U. S. Public Health Service Grant DE-02731.

\section{REFERENCES}

1. Dziewiatkowski, D. D., Hascall, V. C., and Riolo, R. L., Anal. Biochem., to appear.

2. "Procedures Manual" (Amino Acid Analyzer), Beckman, 1966.

3. "Handbook of Biochemistry," p. B20. The Chemical Rubber Co., Cleveland, Ohio, 1968.

4. Robinson, D. S., And Greenstein, J. P., J. Biol. Chem. 195, 383 (1952). 
5. Gross, J., ANd Kirk, D., J. Biol. Chem. 233, 355 (1958).

6. Hamilton, P. B., and Ortiz, P. J., J. Biol. Chem. 187, 733 (1950).

7. Spackman, D. H., Stein, W. H., and Moore, S., Anal. Chem. 30, 1190 (1958)

8. Fischer, E., Ber. 35, 2260 (1902).

9. Wieland, H., ANd Witkop, B., Ann. Chem. 543, 171 (1940).

10. Radhakrishman, A. N., ANd Giri, K. V., Biochem. J. 58, 57 (1954). 